\title{
Docentes para uma educação de qualidade: uma questão de desenvolvimento profissional
}

\section{Teachers for an education with quality}

\begin{abstract}
Maria Izabel de Almeida*
Nesta época, cabe-nos pensar e decidir o curso pelo qual desejamos que transcorra a realidade social e da educação. Apesar de tudo, acreditamos que o nosso trabalho precisa ter um rumo, por mais provisório e consensual que seja; pensamos que a tarefa de educar deve ser dirigida por algumas idéias-mestra plasmadas em projetos compartilhados e assumidos individual e coletivamente. A crise do sistema educativo tem relação com a perda de consciência sobre o seu sentido. (...) A consciência da crise é um estímulo para encontrar novas e renovadas referências.
\end{abstract}

José Gimeno Sacristán

\section{RESUMO}

Preocupados com o futuro das instituições públicas de educação e com a situação de seus professores, discutimos neste texto como as transformações sociais colocam a importância de se redefinir o sentido da escola e assegurar-lhe as condições para o desenvolvimento de uma educação com qualidade social. $\mathrm{O}$ argumento central dessa reflexão sustenta que é preciso investirem políticas para a melhoria da formação dos professores e das condições em que exercem sua profissão. Para nós, esses dois aspectos estão extremamente articulados, com repercussões diretas na qualidade da educação, e devem ser entendidos como dimensões do desenvolvi-

* Professora do Departamento de Metodologias do Ensino e Educação Comparada da Faculdade de Educação da Universidade de São Paulo, na área de Didática. E-mail: mialmei@ usp.br 
mento profissional docente, já que os professores são sujeitos com papel essencial para se viabilizar mudanças no universo da escola. Portanto, argumentamos na direção de que é preciso colocar o professor e o seu trabalho no centro das atenções. Outro foco deste artigo está voltado para qualificar a idéia de qualidade e discutir os elementos necessários para viabilizá-la.

Palavras-chave: formação de professores, desenvolvimento profissional, política educacional, mudanças na escola.

\begin{abstract}
Concerned with the future of public educational institutions and the situation of their teachers, we discuss in this text the necessity to redefine the meaning of the school, and to guarantee the development of a social education facing the social changes. The main argument in this reflection lays in the need to offer a better formation for teachers and better conditions of work. We consider these two aspects as fully intertwined and directly reflected in the quality of the education, so that they must be understood as dimensions of the teachers' professional development, being the teachers subjects with an essential role in any possible change inside the school. Therefore, we believe that it is important to spotlight the teachers and their work. This article also intends to qualify the idea of quality and discuss the necessary elements to make it possible.

Key-words: teachers' formation, professional development, education politics, changes in the school.
\end{abstract}

\title{
Introdução
}

Hoje é consenso afirmar que a vida da escola, dos estudantes e dos educadores está bastante prejudicada pelos desacertos, fragilidades e descompromissos das políticas que vêm sendo adotadas há décadas. Os problemas delas decorrentes têm colocado limites e desconfortos bastante fortes às ações dos que aí convivem, caracterizando, por um lado, uma crise interna. Por outro, também se evidencia, aos olhos da sociedade, uma crise de legitimidade da escola, que é percebida com nuances próprias pelos seus diferentes segmentos, e ganha feições face à evidência da exclusão de amplos setores da população aos bens culturais trabalhados na esfera escolar. 
Para se redefinir o sentido da escola e assegurar que ela tenha a qualidade que os alunos, os pais e a sociedade desejam, há que se levar a sério a idéia, muito presente nos debates, mas não na ação, de que é preciso investir na melhora da formação dos professores e das condições em que eles exercem sua profissão. Ou seja, é preciso colocar o professor e o seu trabalho no centro das atenções. Também é necessário se ter claro que isso só será prioridade se toda a sociedade acreditar que esse é o caminho para melhorar a qualidade de vida e para construir formas mais solidárias de relacionamento social.

Diante de tamanha necessidade, cabe a pergunta: como passar do falar ao fazer? Sem dúvida não é fácil respondê-la. Os caminhos são inúmeros. E o que pretendemos aqui é discutir algumas possibilidades que se colocam para a transformação da situação vivida pelos professores em nosso país.

\section{Ingerências do mundo atual sobre a profissão docente}

Nossa sociedade vive um processo veloz de mudanças, que se faz presente em todos os aspectos da vida. Cotidianamente cada um de nós é chamado a reaprender como se colocar diante das novas demandas e a lutar pela preservação dos nossos direitos, já que esse processo mundializado é orientado pela lógica da exclusão daqueles que não se enquadram nos padrões ditados pelo chamado mercado.

Diante disso não faltam demandas para a escola. Muito se tem discutido a respeito de sua contribuição na construção dos alicerces de uma nova sociedade, voltada para o atendimento do que é essencial à dignidade da vida da maioria da população. Porém, suas práticas nem sempre caminham nessa direção, uma vez que seus problemas crescem em número e em complexidade a cada dia. Vejamos alguns deles.

Nas últimas décadas, a escola brasileira abriu-se para parcelas que estavam até então dela excluídas, passando a trabalhar com crianças e jovens de origens muito diferentes, o que tornou difícil assegurar a todos o sucesso na aprendizagem. Ela passou então a enfrentar a evidência de que a extensão da escolarização não produziu a promoção social dos mais desfavorecidos e começou a conviver com a violência, reflexo da situação social dos bairros degradados ou das grandes cidades. Por conta dessa profunda mudança, a escola já não tem mais clareza a respeito dos objetivos e dos valores com os quais 
deve trabalhar. E por força de interesses diversos, os professores passaram a ser apontados como responsáveis pelas deficiências presentes na escola.

Ao mesmo tempo, novas demandas têm sido colocadas pela reordenação do mundo do trabalho, impulsionadas pelas novas tecnologias, e pelo movimento mundial de globalização. Da escola passou-se a exigir a formação de um novo cidadão trabalhador.

Simultaneamente, verifica-se uma diminuição das responsabilidades educativas de outros agentes sociais, especialmente da família, e um aumento das exigências com relação ao professor, que além de ensinar de maneira competente, deve ser facilitador da aprendizagem, organizador de atividades coletivas, orientador psicológico, social e sexual, além de dar atenção aos alunos com necessidades especiais integrados na sala de aula, já que essa integração está cada vez mais presente em nossas redes de ensino. E para fazer tudo isso, ele continua tendo a mesma formação, que basicamente não se alterou, e que não o prepara para enfrentar os conflitos e os desafios das situações presentes nas escolas.

A esses problemas soma-se a precariedade das condições disponíveis para a realização do ensino às crianças e jovens. Por insuficiência dos recursos destinados à educação, os professores e as escolas têm vivido dificuldades enormes. Os primeiros têm enfrentado um rebaixamento salarial grave e uma desvalorização social de sua profissão sem precedentes. As escolas sofreram intensa deterioração e, como consequiência, têm oferecido condições cada vez mais precárias para o trabalho docente e para o estudo dos alunos. Isso gera sentimentos de fracasso e de frustração, que minam as possibilidades de os professores realizarem um trabalho positivo.

O resultado desse tipo de política, que já dura pelo menos trinta anos, é desastroso. A mesma escola que se abriu, do ponto de vista quantitativo, para uma parcela maior da população, por não promover em si mesma alterações qualitativas, exclui cruelmente do mundo do conhecimento milhares de crianças e jovens. O ensino oferecido nem sempre é compatível com a qualidade social necessária ao exercício da cidadania e à preparação para o mundo do trabalho.

Todos esses fatores apontam a necessidade de se mudar radicalmente a escola, o que significa mudar as práticas dos professores.Várias iniciativas já foram implementadas e outras tantas estão em curso, acompanhando uma tendência reformista, que é internacional. Nesse processo também têm sido produzidos muitos estudos sobre as mudanças, focando os elementos responsáveis pelo sucesso ou pelo fracasso das mesmas. Muitos deles evidenciam que os professores jogam papel determinante no desenvolvimento e no êxito 
dessas transformações, pois são eles, em última instância, que decidem se querem mudar suas práticas ou não.

Esse é um aspecto a ser cuidadosamente considerado, pois um real processo de mudança educacional tem que envolver os professores desde sua fase de elaboração e tem que prever um programa de formação contínua capaz de responder aos novos desafios que eles enfrentarão. Sem essas condições, a mudança não sairá do papel ou será implantada de forma caricata, provocando resistências nos professores.

\section{As necessidades para a realização de uma educação de qualidade}

Se hoje nos debatemos com a necessidade de termos políticas que promovam a transformação das condições educacionais, assegurando uma educação com qualidade social aos freqüentadores de nossas escolas, cabem aí duas perguntas centrais: de que qualidade se está falando e o que é necessário para viabilizá-la?

Vamos à primeira. A expressão educação de qualidade está presente nos mais variados discursos: nas políticas educacionais; nos pronunciamentos de governantes e políticos, tanto dos compromissados com os segmentos sociais que freqüentam a escola pública como daqueles que a usam como biombo para a defesa de interesses privatistas; nas formulações elaboradas por pesquisadores da área educacional; nas análises e propostas dos organismos representativos dos professores; nas falas de lideranças dos mais variados segmentos sociais; nas mídias etc.

Mais grave ainda é a estratégia de se alcançar a qualidade total, trazendo os modos de organização empresarial para dentro das escolas, abandonando as preocupações com a qualidade do ensino como direito dos cidadãos e adotando os referenciais da produtividade e da competitividade. Com isso, a qualidade é transformada num valor de mercado, servindo à corrida competitiva.

Portanto, a idéia de educação de qualidade esvaziou-se, tornando-se um consenso inútil, que não unifica os esforços nem contribui para uma ação capaz de viabilizá-la. Isso torna necessário qualificarmos a qualidade que queremos.

A bandeira da qualidade na educação vem sendo construída e defendida pelo movimento social, pedagógico e cultural em nosso país há várias décadas. Ao longo desse tempo, ela veio ganhando adjetivações. Uma delas resul- 
ta na expressão qualidade sociocultural. Terezinha RIOS (2001), contribui para entendermos essa qualificação. Ela diz que a qualidade sociocultural da educação passa pela construção de um espaço público que reconheça as diferenças e os direitos iguais nas diferenças; pela renovação dos conteúdos críticos e da consciência crítica dos profissionais; pela resistência a uma concepção mercantilizada e burocratizada do conhecimento; pelo alargamento da função social e cultural da escola; pela intervenção nas estruturas excludentes do velho e seletivo sistema escolar.

CORTELLA (2000) afirma que, para se alcançar a qualidade social na educação, é preciso uma sólida base científica, capaz de oferecer uma formação crítica de cidadania e desenvolver a solidariedade de classe social. Uma escola orientada nessa perspectiva deve selecionar e apresentar conteúdos que possibilitem aos alunos uma compreensão de sua própria realidade e seu fortalecimento como cidadãos e, ao mesmo tempo, prepará-los para transformála na direção dos interesses da maioria social.

Esses dois argumentos nos mostram que uma educação com qualidade social precisa considerar as necessidades das camadas que freqüentam a escola pública a partir da realidade sociocultural. Para isso, há que se garantir a universalização do acesso à escola básica, sua gratuidade e um ensino de alto nível como direito dos cidadãos e dever do Estado. Essa deve ser a direção de uma política pública que realmente esteja voltada para o atendimento do conjunto da sociedade.

\section{O professor necessário}

Esperando que o conceito de qualidade social da educação esteja mais claro, vamos discutir agora o papel dos professores para viabilizá-la. Com o passar do tempo, as sociedades mudam e se desenvolvem, transformando também suas necessidades. E a escola precisa responder a elas, o que cobra dos professores uma atualização constante em sua atuação. Especialmente neste início de século, quando convivemos com uma verdadeira avalanche de inovações científicas e tecnológicas, que apontam para uma organização bastante diferenciada do mundo, o papel dos professores não pode continuar a ser o mesmo.

Como deve ser o professor que acompanhará as novas gerações em seu desenvolvimento? 
Muitos, a partir de variadas perspectivas teóricas, têm se esforçado em responder a essa pergunta. E o ponto de unificação entre algumas dessas respostas vai na direção de um professor capaz de desenvolver uma nova forma de relacionamento com seus alunos, preparando-os para entrar em contato com o mundo do conhecimento, de modo a apropriar-se dele, articulando as novas aprendizagens com as anteriores, e a tornar-se um produtor de conhecimentos numa perspectiva interdisciplinar. Uma outra dimensão, também muito valorizada da prática docente, é a capacidade do professor empenhar-se na formação de seus alunos para a democracia, o que requer disposição para uma convivência com eles enquanto pessoas e enquanto cidadãos, contribuindo para que tenham uma melhor inserção em nosso mundo.

Diante desse conjunto de atribuições, NóvoA (1999, p. 20) nos diz que "a refundação da escola tem muitos caminhos, mas todos eles passam pelos professores. Esta profissão representou, no passado, um dos lugares onde a idéia de escola foi inventada. No presente, o seu papel é essencial para que a escola seja recriada como espaço de formação individual e de cidadania democrática. Mas para que tal aconteça é preciso que os professores sejam capazes de refletirem sobre a sua própria profissão, encontrando modelos de formação e de trabalho que lhes permitam não só afirmar a importância dos aspectos pessoais e organizacionais da vida docente, mas também de consolidar as dimensões coletivas da profissão."

Como se vê, é grande a agenda que compete aos professores nessa maré de transformações. Mas, ao mesmo tempo em que vemos uma valorização do seu papel no campo das pesquisas educacionais e também nos projetos e nos discursos políticos, é preciso dizer que o reconhecimento real dessa importância é muito pequeno. Na maioria das vezes, eles são reduzidos a meros executores de ações que outros definem como inovadoras, exercendo sua ação profissional em situações que, nem de longe permitem a concretização dos objetivos apontados ainda há pouco e são muito mal pagos pelo trabalho que realizam.

Vejamos então como se configuram alguns elementos definidores das condições em que os professores vêm realizando o seu trabalho nas últimas décadas:

a) política educacional descomprometida com a educação de qualidade para todos: isso abre espaço para práticas pouco sérias na aplicação dos recursos públicos, desqualifica a formação das crianças e jovens, agrava o empobrecimento da escola pública e o correspondente favorecimento da privatização do ensino;

b) baixos salários: fruto da política de arrocho expressa a baixa valorização da profissão e faz com que os professores assumam a cada 
ano um número maior de aulas, exterminando o tempo que seria dedicado às atividades didáticas correlacionadas às aulas e ao estudo, o que tem incidência direta na qualidade do trabalho realizado, bem como na sua vida pessoal;

c) separação entre concepção e execução da prática educacional e a desvalorização dos professores: essa concepção coloca-os no papel de meros executores de diretrizes educacionais, propostas curriculares ou materiais didático-pedagógicos elaborados por especialistas, o que reforça o controle externo sobre a atuação docente e contribui para o enfraquecimento, esvaziamento e desvalorização da profissão;

d) precariedade da formação inicial e ausência de formação contínua: a pouca seriedade com que os cursos de formação inicial têm sido conduzidos e a ausência de políticas de formação contínua no interior dos sistemas de ensino têm enfraquecido a capacidade de atuação dos professores e contribuído para o empobrecimento da escola;

e) autoritarismo na gestão da escola e na implantação das mudanças educacionais: $o$ autoritarismo presente em nossa sociedade durante décadas está ainda bastante vivo nas escolas. Na maioria dos casos, sua gestão é marcada por um verticalismo que marginaliza os profissionais, os alunos e a comunidade. Isso dificulta o desenvolvimento de uma cultura de colaboração, de envolvimento com a dimensão coletiva da vivência escolar. O mesmo acontece ao implantar processos de mudanças educacionais, que são gestadas por técnicos e políticos, chegando às escolas na forma de "pacotes";

f) deterioração das condições de trabalho e desestímulo à ação docente: o trabalho dos professores vem sendo realizado em condições cada vez mais precárias. Combinada com a sobrecarga de trabalho, essa deterioração tem efeitos físicos e psicológicos nefastos sobre os professores, gerando sensações de frustração e provocando desestímulo à sua atuação;

g) jornada de trabalho não contempla as necessidades dos professores e reforça o trabalho individual: a elevada carga de trabalho semanal, fruto da pauperização e da intensificação do trabalho docente, faz com que os professores atuem de maneira dispersa, trocando de escolas e de classes a todo momento. Não há tempo para a organização do trabalho, para o estudo e muito menos para atuações coletivas, acabando por fortalecer o isolamento dos professo- 
res. Eles não têm tempo para o convívio com colegas e para atuar em projetos ou atividades interativos;

h) carreira docente inadequada, longe da realidade de trabalho: isso acaba por desestimular o investimento dos professores na própria trajetória profissional. A progressão é feita de maneira burocrática, voltada exclusivamente para a dimensão individual, premiando o tempo de serviço e a realização de cursos de extensão ou aperfeiçoamento. Ignora-se o envolvimento real com o trabalho e a dedicação às ações coletivas, bem como a qualidade do que foi realizado.

Apontar esse conjunto de fatores que oferecem os contornos e limitam a atuação docente, não significa minimizar a responsabilidade dos próprios professores nos processos de qualificação de seu trabalho. Mas não fazê-lo pode abrir espaço para que eles sejam os únicos a serem responsabilizados pela realização de uma educação com qualidade social. Por isso, é importante identificar como as áreas que competem a outros agentes têm interferência na qualidade do trabalho docente. Uma vez colocado o quadro problemático da educação, vamos agora discutir a formação e as condições de trabalho necessárias para que os professores possam responder às demandas que lhes são postas e viabilizar uma prática pedagógica consonante com as necessidades sociais.

\section{Organizar a formação dos professores na perspectiva do seu desenvolvimento profissional}

Em sua atuação profissional, o professor toma decisões diante das situações concretas do dia-a-dia e para isso lança mão de um conjunto de conhecimentos específicos. Ele também estabelece relações com seus pares e com o espaço escolar como um todo. É na combinação dessa base de conhecimentos teóricos com a prática que, o professor vai adequando sua formação às exigências de sua atividade profissional, num processo contínuo de desenvolvimento profissional.

Dar conta de gerir o processo de ensino-aprendizagem na perspectiva da qualidade social exige um profissional que:

- domine a área específica de conhecimento na qual ele aprofundou seus estudos e domine os saberes didático-pedagógicos, necessários na mediação de sua relação com os alunos e o conhecimento; 
- $\quad$ assuma de maneira responsável os compromissos éticos e as responsabilidades da profissão;

- participe da gestão coletiva da escola e partilhe os aspectos coletivos do trabalho docente;

- coordene sua formação contínua na perspectiva do seu desenvolvimento profissional, reconfigurando sua identidade profissional individual e coletiva;

- $\quad$ estabeleça boas relações com os colegas e outros profissionais da área, com alunos, pais e a comunidade.

Para dar conta de tamanho desafio é preciso entender que o professor está sempre em processo de formação, o que ocorre quando ele está estudando, preparando suas atividades, refletindo sobre os desafios da prática, se relacionando com os alunos ou colegas. Entender dessa maneira a formação do professor requer pensá-lo em suas dimensões coletiva, profissional e organizacional, contribuindo para a sua emancipação profissional e para a autonomia na produção dos seus saberes e valores. Significa também reconhecer que o processo de aprender a ensinar se prolonga durante toda a carreira docente. FUSARI (1998) nos propõe a idéia de que a formação contínua é infinita enquanto possibilidade de crescimento pessoal e profissional do educador e precisa estar centrada na reflexão crítica que deve ocorrer na experiência profissional a partir dos saberes advindos dela.

Como a prática do professor desenvolve-se na escola, a sua melhora profissional leva à melhora da instituição e vice-versa. Para reforçar essa idéia, NóvoA (1992, p. 28) nos diz que "as escolas não podem mudar sem o empenhamento dos professores; e estes não podem mudar sem uma transformação das instituições em que trabalham. O desenvolvimento profissional dos professores tem de estar articulado com as escolas e os seus projetos". Em outras palavras, o desenvolvimento pessoal e profissional do professor é produzido dentro do contexto de desenvolvimento da sua escola, e nessa medida envolve não apenas o professor, mas toda pessoa com responsabilidade ou implicação na melhora da escola, sejam diretores, coordenadores, pessoal de apoio etc. O desenvolvimento profissional do professor e a melhora institucional escolar são duas faces da mesma moeda.

Assim o desenvolvimento profissional tem como aspecto essencial uma política de formação de professores e requer uma série de condições que têm sido ignoradas ou insatisfatoriamente resolvidas pelas políticas educacionais em nosso país como: carreira docente, jornada de trabalho, salário, condições de trabalho, bem-estar dos professores, espaços coletivos para se enfrentar as questões educacionais e profissionais etc. 
Essas demandas colocam a todos nós, professores, em constante processo de formação, a necessidade de buscarmos respostas capazes de reconfigurar a profissão docente na direção de uma nova profissionalização, capaz de responder às exigências da diversidade e da mudança, marcas deste nosso tempo.

Ou seja, "pensar a prática não é somente pensar a ação pedagógica na sala de aula nem mesmo a colaboração didática com os colegas. É pensar a profissão, a carreira, as relações de trabalho e de poder nas organizações escolares, a autonomia e a responsabilidade conferida aos professores, individual ou coletivamente" (PERRENOUd, 1993, p. 200).

A constituição de um novo profissionalismo docente, centrado no desenvolvimento profissional dos professores, poderá contribuir para enfrentar os fatores que lhes criam preocupações, dificuldades e inseguranças, na medida em que lhes permitirá atuar com mais criatividade e eficiência, redimensionar o ser professor e caminhar na sua auto-construção pessoal e profissional com autonomia.

\section{REFERÊNCIAS}

ALMEIDA, M. I. O sindicato como instância formadora dos professores: novas contribuições ao desenvolvimento profissional. São Paulo, 1999. Tese (Doutorado) Feusp.

Os professores diante das mudanças educacionais. In: BICUDO, M. A.; SILVA JÚNIOR, C. A. (Orgs.). Formação do educador e avaliação educacional. São Paulo: Unesp, 1999.

CORTELLA; M. S. A escola e o conhecimento: fundamentos epistemológicos e políticos. São Paulo: Cortez/Inst. Paulo Freire, 2000.

CUNHA, M. I. da. Profissionalização docente: contradições e perspectivas. In: VEIGA, I. P. A.; CUNHA, M. I. da (Orgs). Desmistificando a profissionalização do magistério. Campinas: Papirus, 1999.

FUSARI, J. C. Formação contínua de educadores - um estudo de representações de coordenadores pedagógicos da Secretaria Municipal de Educação de São Paulo. São Paulo, 1998. Tese (Doutorado) - Feusp.

NÓVOA, A. (Coord.). Os professores e sua formação. Lisboa: Dom Quixote, 1992. 
NÓVOA, A. Os professores na virada do milênio: do excesso dos discursos à pobreza das práticas. Educação e Pesquisa, v. 25, n. 1, 1999.

PERRENOUD, P. Práticas pedagógicas, profissão docente e formação: perspectivas sociológicas. Lisboa: Dom Quixote, 1993.

RIOS, T. A. Compreender e ensinar: por uma docência da melhor qualidade. São Paulo: Cortez, 2001.

Texto recebido em 27 fev. 2004 Texto aprovado em 14 jul. 2004 